\title{
IMPLEMENTASI PROGRAM LITERASI BUDAYA MELALUI SANGGAR DONGENG ANAK DI DESA MOROREJO SLEMAN
}

\author{
Yora Harlistyarintica, Ririn Nikmatul Kuffa, Sigit Apriyanto, Susi, Nur \\ Cholimah \\ PAUD FIP Universitas Negeri Yogyakarta \\ e-mail: yora.harlistya@gmail.com, ririnnikma5@gmail.com, \\ sigitapriyanto44@gmail.com, susione540@gmail.com, nurcholimah@uny.ac.id
}

\begin{abstract}
Abstrak
Program ini bertujuan untuk menggerakkan literasi atau melek budaya (salah satu unsur budaya: sistem mata pencaharian) dengan cara mendongengkan cerita pada anak-anak. Sehingga cerita-cerita yang didongengkan untuk anak-anak seperti cerita tentang kebiasaan petani bercocok tanam ke sawah, ladang, dan beternak. Metode yang digunakan dalam program ini berupa metode dongeng, bernyanyi, bermain, tanya jawab, karyawisata, penugasan, dan demonstrasi. Kegiatan yang dilakukan berupa mendengarkan cerita, membuat media cerita, bercerita, menggambar, dan jalanjalan/karyawisata. Sasaran kegiatan ini berjumlah 10 anak berusia 4-8 tahun dari Dusun Plumbon Tengah, Mororejo, Tempel, Sleman. Pendidik dalam kegiatan ini yaitu tim pelaksana program kreativitas mahasiswa Program Literasi Budaya melalui Sanggar Dongeng Anak. Hasil dari kegiatan ini anak mampu menggambar dan bercerita tentang budaya (salah satu unsur: sistem mata pencaharian) di Desa Mororejo. Hasil cerita anak tersebut kemudian ditulis oleh tim program kreativitas mahasiswa yang kemudian dikumpulkan untuk dibukukan. Anak-anak terlihat antusias selama mengikuti kegiatan. Orang tua sangat mendukung kegiatan ini terlihat dari keterlibatannya dalam mendampingi anak.
\end{abstract}

Kata Kunci: literasi budaya, sanggar dongeng, anak

\begin{abstract}
This program heads to actuate the cultural literacy (particularly in livelihood aspect) through storytelling for children. The story that being told are about farming and animal caring. The methods that used are storytelling, playing a game, singing, questions and answers, study tours, task and demonstration. The activities are listening to a story, making a media, storytelling, drawing and study tour. The targets are ten children with age four until eight years from Plumbon Tengah orchard, Mororejo, Sleman. The educators are the implementer team of college creativity program in Cultural Literacy through story studio for children. The result of this program is expected for the children to be able to draw and telling their heritage (one of the professions) in Mororejo Village. The result, that is the stories are then collected and being made into a book. The children seem excited and the parents also vote for the program by supporting their children.
\end{abstract}

Keyword: cultural literacy, story studio, children 


\section{PENDAHULUAN}

Sleman lekat kaitannya dengan budaya Yogyakarta. Slogan Sleman Sembada sarat akan nilai-nilai budaya, dimana sembada adalah suatu sikap ksatria, bulat tekad, kukuh, dan mengabdi bagi kepentingan, dan kesejahteraan bersama.

Menurut Koentjaraningrat kata "kebudayaan" berasal dari kata Sansekerta buddhaya, yaitu bentuk jamak dari buddhi yang berarti "budi atau akal. Sedangkan kata "budaya" adalah "daya dan budi" yang berupa cipta, karsa, dan rasa. Sehingga kebudayaan dapat diartikan sebagai hasil dari cipta, karsa, dan rasa itu (2009:146). Lebih lanjut, kebudayaan memiliki tujuh unsur kebudayaan yaitu bahasa, sistem pengetahuan, organisasi sosial, sistem peralatan hidup, sistem mata pencaharian hidup, sistem religi, dan kesenian (Koentjaraningrat, 2009:165).

Salah satu Desa di Sleman yang memiliki potensi kebudayaan untuk dilestarikan yaitu Desa Mororejo. Unsur kebudayaan yang paling menonjol di Desa Mororejo yaitu pada sistem mata pencaharian. Sistem mata pencaharian di Desa Mororejo yaitu bercocok tanam (padi, jagung, tanaman hortikultura) dan beternak (sapi, kambing, bebek, ayam). Pada tahun 2016 desa ini juga dicanangkan menjadi desa mandiri pangan lokal oleh Pemerintah Kabupaten Sleman (www.republika.co.id diakses pada 09 November 2017 pukul 23.46 WIB).

Namun, berbagai permasalahan muncul di Desa Mororejo khususnya di Dusun Plumbon Tengah. Berdasarkan hasil wawancara dengan Bapak Ismail Hanafi selaku Kepala Dukuh Plumbon Tengah, Mororejo, Tempel, Sleman ada beberapa permasalahan yang cukup krusial. Permasalahan tersebut antara lain: (1) Anak-anak cenderung kurang memahami mata pencaharian orangtuanya; (2) Taman Bacaan Masyarakat Asmaina belum memiliki variasi buku bacaan dan kegiatan yang berhubungan dengan literasi budaya (sistem mata pencaharian) (09/11/2017).

Alternatif pemecahan masalah yang dapat dilakukan oleh tim PKM adalah bermitra dengan TBM Asmaina untuk mengembangkan program yang berhubungan dengan literasi budaya. Tim PKM mengembangkan dengan metode mendongengkan cerita pada anak-anak.

\section{Pentingnya Mendongengkan Cerita pada Anak Usia Dini}

Menurut NAEYC (National Association for The Education Young Children) anak usia dini adalah anak yang berumur nol tahun hingga berusia kurang lebih delapan tahun (Santoso dalam Musfiroh, 2005). Periode tersebut merupakan usia emas dalam tahap perkembangannya untuk dapat mengenal fakta di lingkungan sekitarnya. Hal tersebut sebagai stimulasi untuk mengembangkan aspek bahasa, sosial, emosional, kognitif, dan fisik motoriknya. Selain itu, dalam periode ini anak usia dini sebagai peniru ulung apa yang ada di lingkungan sekitarnya. Mengingat, anak usia tersebut belum mengetahui batasan benar dan salah. Oleh karenanya masa ini juga sering disebut sebagai masa peka terhadap pengaruh dari lingkungan. Sehingga masa ini juga memberikan kesempatan bagi orangtua, guru maupun orang dewasa yang ada disekeliling anak untuk dapat berperan dalam mendidik perilaku anak agar memiliki perilaku yang positif. Salah satu cara yang dapat dilakukan dengan kegiatan mendongengkan cerita bagi anak usia dini.

Cerita dapat digunakan oleh orang tua, guru, maupun orang dewasa sebagai sarana mendidik dan membentuk kepribadian anak melalui pendekatan transmisi budaya atau cultural transmission approach (Suyanto \& Abbas dalam Musfiroh, 2005). Lebih lanjut Menurut Gunarti, Suryani \& Muis (2008), 
tujuan yang ingin dicapai dalam kegiatan bercerita atau mendongeng adalah :

1. Mengembangkan kemampuan berbahasa, diantaranya kemampuan menyimak (listening), juga kemampuan dalam berbicara (speaking) serta menambah kosakata yang dimilikinya.

2. Mengembangkan kemampuan berpikirnya karena dengan bercerita anak diajak untuk memfokuskan perhatian dan berfantasi mengenai jalan cerita serta mengembangkan kemampuan berpikir secara simbolik.

3. Menanamkan pesan-pesan moral yang terkandung dalam cerita yang akan mengembangkan kemampuan moral dan agama.

4. Mengembangkan kepekaan sosialemosional anak tentang hal-hal yang terjadi di sekitarnya melalui cerita yang disampaikan.

5. Mengembangkan potensi kreatif anak melalui keragaman ide cerita yang disampaikan.

\section{METODE}

Metode kegiatan ini dilaksanakan melalui tiga tahap yaitu prapelaksanaan, pelaksanaan, dan pascapelaksanaan. Prapelaksanaan merupakan tahap persiapan untuk pelaksanaan program. Pelaksanaan merupakan realisasi program. Pascapelaksanaan merupakan evalusai dan monitoring program yang telah dilakukan.

\section{Prapelaksanaan}

Pada tahap ini terdapat beberapa kegiatan seperti: 1) menjalin kerjasama dengan mitra program yaitu Ketua TBM Asmaina; 2) Mengajukan permohonan ijin pelaksanaan kegiatan dengan Kepala Dukuh Plumbon Tengah, Mororejo, Tempel, Sleman; 3) membuat timeline kegiatan; 4) menyusun job desk dan membagi job desk kepada anggota kelompok PKM; 5) membuat modul kegiatan; 6) membuat silabus dan rencana pelaksanaan program; 7) membeli bukubuku cerita; 8) menyiapkan alat dan bahan; 9) menyiapkan media kegiatan; 10) sosialisasi kegiatan; 11) membagikan undangan ke anak-anak.

\section{Pelaksanaan}

Tahap pelaksanaan dilakukan sebanyak delapan pertemuan dengan berbagai kegiatan diantaranya: mendengarkan cerita, membuat media cerita, bercerita, menggambar, dan karyawisata/jalan-jalan. Metode yang digunakan dalam program ini berupa metode dongeng, benyanyi, bermain, karyawisata, dan demonstrasi. Sasaran kegiatan ini berjumlah 10 anak dari Dusun Plumbon Tengah, Mororejo, Tempel, Sleman.

\section{Pascapelaksanaan}

Tahap pascapelaksanaan dilakukan dengan evaluasi program yang telah dilakukan secara menyeluruh. Evaluasi keseluruhan pelaksanaan program bertujuan untuk mengetahui ketercapaian target luaran program yang telah dilaksanakan. Evaluasi ini dilakukan dengan adanya wawancara (tanya jawab) dan observasi. Wawancara (tanya jawab) dilakukan sebelum dan sesudah kegiatan yang bertujuan untuk mengetahui pengetahuan anak. Observasi (pengamatan) juga dilakukan untuk mengetahui dampak pelaksanaan selama proses pelaksanaan sampai setelah pelaksanaan kegiatan. Kemudian tingkat kebermanfaatan program juga diungkapkan dengan adanya testimoni (kesan pesan) dari pihak-pihak terkait (orangtua/wali peserta program, ketua TBM Asmain, kepala dukuh Plumbon Tengah, Mororejo, Tempel, Sleman, Yogyakarta).

\section{HASIL DAN PEMBAHASAN \\ Hasil}

Hasil dari Program Kreativitas Mahasiswa bidang Pengabdian Masyarakat (PKM-M) ini melibatkan 
sasaran sebanyak 12 anak berusia 4-8 tahun yang berasal dari Dusun Plumbon Tengah, Mororejo, Tempel, Sleman, Yogyakarta. Berikut deskripsi kegiatannya:

\section{Kegiatan pertama}

Kegiatan pertama yaitu anak-anak diminta untuk mendengarkan dongeng Dewi Sri. Tujuannya adalah untuk mengenalkan kehidupan pertanian menggunakan media tanaman padi. Kegiatan dilaksanakan pada tanggal 29 April 2018 pukul 09.00-12.00 WIB di TBM Asmaina. Kegiatan tersebut diawali dengan perkenalan diri, permainan (bermain permainan ular naga), dan bernyanyi. Kemudian dilanjutkan dengan mendengarkan cerita Dongeng Dewi Sri. Cerita didongengkan langsung oleh perwakilan tim PKM dan mitra program.

\section{Kegiatan kedua}

Kegiatan kedua yaitu anak-anak diminta untuk mendengarkan dongeng dengan media buku cerita bergambar. Buku cerita bergambar yang digunakan berjudul Qonita di Sawah dan Qonita di Ladang. Tujuannya adalah untuk mengenalkan lahan pertanian (sawah dan ladang). Kegiatan dilaksanakan pada tanggal 12 Mei 2018 pukul 13.00-16.00 WIB di TBM Asmaina. Kegiatan tersebut diawali dengan mengenalkan lahan pertanian yang ada dalam buku cerita. Kemudian tim PKM bersama mitra mendongengkan cerita pada anak-anak.

\section{Kegiatan ketiga}

Kegiatan ketiga yaitu anak-anak diminta membuat media boneka wayang. Tujuannya adalah untuk mengenalkan figur petani. Kegiatan tersebut diawali dengan mengenalkan figur petani. Kemudian tim PKM bersama mitra mengajarkan cara membuat media boneka wayang tersebut. Alat dan bahan yang dibutuhkan yaitu kardus bekas, lem, spidol, gunting, crayon, lidi, tali, gambar wayang. Berikut cara membuat boneka wayangnya: 1) Warnailah gambar wayangnya; 2) Guntinglah gambar wayang yang telah diwarnai; 3) Tempelkan pada kardus bekas; 4) Guntinglah wayang tersebut; 5) Berilah lubang dibagian tangannya kemudian diberi lidi dan diikat dengan tali. Kegiatan dilaksanakan pada tanggal 19 Mei 2018 pukul 13.00-16.00 WIB di TBM Asmaina.

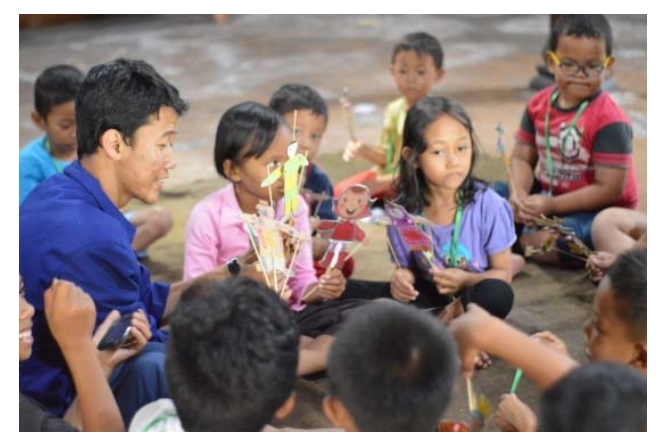

Gambar 01. Tim PKM sedang mengenalkan figur seorang petani menggunakan media boneka wayang

\section{Kegiatan keempat}

Kegiatan keempat yaitu karyawisata mengunjungi sawah dan ladang. Tujannya adalah agar anak dapat mengamati kegiatan petani secara konkrit. Kegiatan dilaksanakan pada tanggal 26 Mei 2018 pukul 13.00-16.00 WIB.

\section{Kegiatan kelima}

Kegiatan kelima yaitu menggambar dan bercerita. Tujuannya adalah agar anak-anak dapat memvisualisasikan apa yang mereka pahami dari pertemuan 1-4.

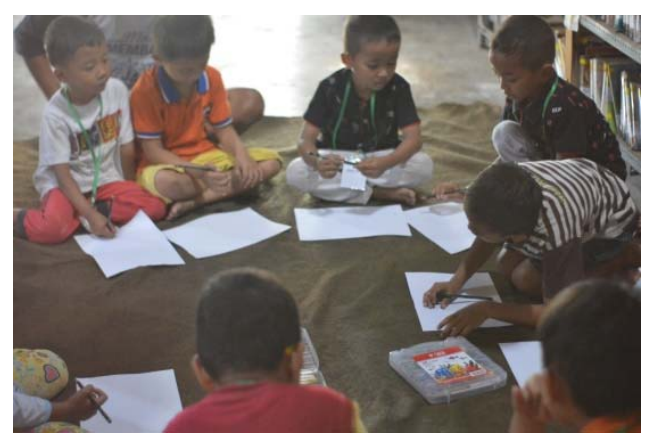

Gambar 02. Anak-anak sedang menggambar 
Kegiatan dilaksanakan pada tanggal 27 Mei 2018 pukul 09.00-12.00 WIB di TBM Asmaina.

\section{Kegiatan keenam}

Kegiatan keenam yaitu anak-anak diminta untuk mendengarkan dongeng dengan media buku cerita bergambar. Buku cerita bergambar yang digunakan berjudul Qonita Menggembala Kambing dan Qonita dan Peternak Ayam.

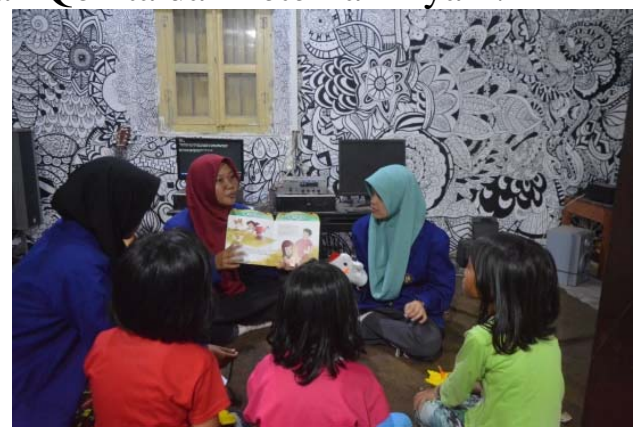

Gambar 03. Tim PKM sedang mendongeng dengan media buku cerita bergambar

Tujuannya adalah untuk mengenalkan kegiatan beternak. Kegiatan dilaksanakan pada tanggal 02 Juni 2018 pukul 13.00-16.00 WIB di TBM Asmaina.

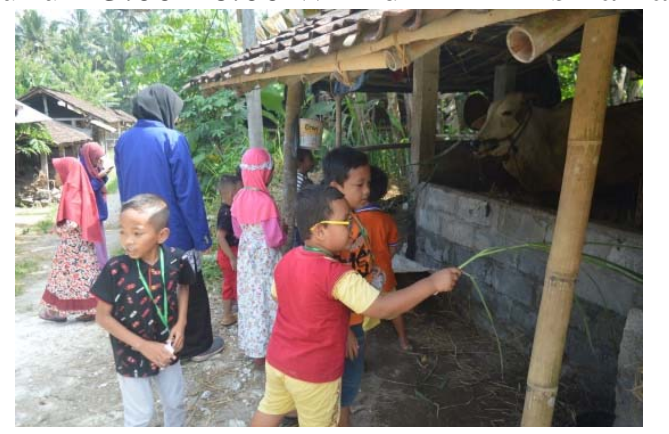

Gambar 04. Anak-anak sedang mengunjungi peternakan sapi

\section{Kegiatan ketujuh}

Kegiatan ketujuh yaitu anak-anak diminta untuk membuat boneka tangan dari kain flanel. Tujuannya adalah untuk mengenalkan berbagai jenis hewan ternak (seperti ayam, sapi, kambing). Alat dan bahan yang dibutuhkan yaitu kain flanel, lem kain, spidol, gunting, kertas HVS, pensil, dan penghapus. Berikut cara membuat boneka tangannya: 1) Buatlah pola boneka diatas kertas HVS; 2) Guntinglah pola tersebut; 3) Letakkan pola di atas kain flanel kemudian guntinglah; 4) Berilah lem kain pada bagian yang membutuhkan lem; 5) Tempelkan mata, hidung, dan mulut dari kain flanel; 6) Berilah tambahan hiasan sesuai kreativitas. Kegiatan dilaksanakan pada tanggal 03 Juni 2018 pukul 09.0012.00 WIB di TBM Asmaina.

\section{Kegiatan kedelapan}

Kegiatan kedelapan yaitu karyawisata mengunjungi lokasi peternakan (sapi, kambing, bebek, ayam). Tujuannya adalah agar anak anak dapat mengamati kegiatan beternak secara konkrit. Kegiatan dilaksanakan pada tanggal 09 Juni 2018 pukul 13.00-16.00 WIB.

\section{Kegiatan kesembilan}

Kegiatan kesembilan yaitu menggambar dan bercerita. Tujuannya adalah agar anak-anak dapat memvisualisasikan apa yang mereka pahami dari pertemuan 6-8. Kegiatan dilaksanakan pada tanggal 10 Juni 2018 pukul 09.00-12.00 WIB di TBM Asmaina.

\section{Pembahasan}

Program Literasi Budaya melalui Sanggar Dongeng Anak yang bermitra dengan TBM Asmaina telah memberikan dampak bagi anak maupun TBM. Setelah dilaksanakan dan dievaluasi, secara keseluruhan anak-anak memahami materi yang diberikan dengan menggunakan metode mendongeng. Selanjutnya anakanak juga sangat menyukai metode mendongeng yang diberikan.

Kemudian, secara keseluruhan anak-anak senang mengikuti kegiatan. Beberapa anak mengungkapkan kesan pesannya melalui tulisan di selembar kertas. 


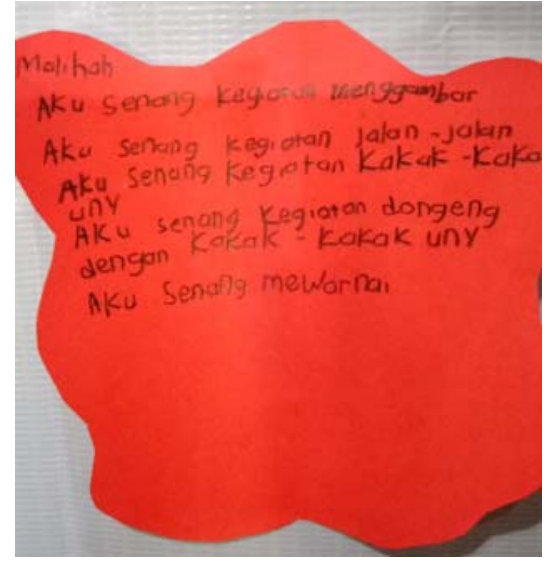

Gambar 05. Ungkapan Kesan Pesan Malihah (salah satu peserta program)

Lebih lanjut, Hasil dari kegiatan ini anak mampu menggambar dan bercerita tentang sistem mata pencaharian di Desa Mororejo. Hasil cerita anak tersebut kemudian ditulis oleh tim program kreativitas mahasiswa yang kemudian dikumpulkan untuk dibukukan.

\section{KESIMPULAN}

Program Literasi Budaya melalui Sanggar Dongeng Anak dapat menggerakkan literasi budaya (salah satu unsur budaya: sistem mata pencaharian) pada anak-anak di Dusun Plumbon Tengah, Mororejo, Tempel, Sleman. Hal tersebut ditunjukkan dari antusias anakanak ketika mendengarakan cerita dengan berbagai metode dongeng serta hasil karya anak-anak yang sedang dalam proses pembuatan buku.

\section{DAFTAR PUSTAKA}

Gunarti, Winda, Suryani, Lilis \& Muis, Azizah. 2008. Metode Pengembangan Perilaku dan Kemampuan Dasar Anak Usia Dini. Jakarta : Universitas Terbuka.

Koentjaraningrat. 2009. Pengantar Ilmu Antropologi. Jakarta: Rineka Cipta.

Musfiroh, Tadkiroatun. 2005. Bercerita Untuk Anak Usia Dini. Jakarta :
Departemen Pendidikan Nasional Direktorat Jenderal Pendidikan Tinggi Direktorat Pembinaan pendidikan Tenaga Kependidikan Dan Ketenagaan Perguruan Tinggi.

Zuraya, Nidia. 2016. Pemkab Sleman Kembangkan Delapan Desa Mandiri Pangan. Diakses dari www. republika.co.id pada 09 November 2017 pukul 23.46 WIB. 